\title{
Recycling and elimination of wastes obtained from agriculture by using nanotechnology: nanosensors
}

\begin{abstract}
In the friction process of two materials and in the presence of some proper lubricants, the wear process manifest itself as a material transfer from an element of the friction couple on the other, process specific to the selective transfer mechanism. The selective transfer can be sure achieved in a friction couple if there is a favorable energy, the relative movement and if in the friction area is a material made by copper and the lubricant is adequate (glycerin). The selective transfer mechanism is characterized by the physicochemical processes, which take place in the contact zones of the friction couples, and which to allow the selective transfer of some elements of the materials from a surface to the other, forming a thin superficial layer with the superior properties at wear and friction. This is a condition for any friction couple of high efficiently and a normal self-adjusting phenomena. The forming of this layer on the contact surfaces makes as fiction force to be reduced. It is in closely related to the structure formed by the selective transfer, between the metallic friction surfaces and with the properties these surface layers metallic.
\end{abstract}

The most important parameters concerning the physical state of the superficial layers are micro-tensions, the structure and its modification on friction surfaces, the structure defects as well as the way of distribution of the additions and of the alloying elements from alloy. The purpose of the present paper is research these parameters by the structural analysis with X-rays, as the research method of the thin superficial layers.
Volume 3 Issue 5 - 2017

\author{
Alvarado MA,' Guzmán ON,' Solís NM,' \\ Vega-Baudrit $]^{1,2}$ \\ 'Universidad Nacional, Costa Rica \\ ${ }^{2}$ Laboratorio Nacional De Nanotecnología lanotec-cenat- \\ conare, Costa Rica
}

Correspondence: Vega-Baudrit J, Escuela De Química, Universidad Nacional, Heredia, Costa Rica,

Email jvegab@gmail.com

Received: October 02, 2017 | Published: December 22, 2017

Keywords: selective transfer, superficial layer, structural analysis, intensity x-rays, width of diffraction lines, crystalline network constant

\section{Environmental importance of the use of agricultural waste}

Primarily is important to make awareness on the large quantities of agricultural/food waste that is lost every year, minute and second around the world. It estimates that each year, approximately one-third food produced for human consumption in the world is lost or wasted. The global volume of food wastage is estimated to be 1.6 Gtonnes of "primary product equivalents", while the total wastage for the edible part of food is 1.3 Gtonnes. This amount can be weighed against total agricultural production (for food and non-food uses), which is about 6 Gtonnes. ${ }^{1}$ Without accounting for GHG emissions from land use change, the carbon footprint of food produced and not eaten is estimated to 3.3 Gtonnes of $\mathrm{CO}_{2}$ equivalent: as such, food wastage ranks as the third top emitter after USA and China. Globally, the blue water footprint (i.e. the consumption of surface and groundwater resources) of food wastage is about $250 \mathrm{~km}$, which is equivalent to the annual water discharge of the Volga river, or three times the volume of Lake Geneva. With such situations, it seems clear that a reduction of food wastage at global, regional, and national scales would have a substantial positive effect on natural and societal resources. Food wastage reduction would not only avoid pressure on scarce natural resources but also decrease the need to raise food production by 60 percent to meet the 2050 population demand. ${ }^{1}$ Fortunately, different kinds of methods have been proposed for reuse agricultural waste instead of remain in the environment. These residues occurred by processing, production and harvest of cereal products, fruits, vegetables and trees, and through stock farming. They are produced in large amounts worldwide and either burnt in the field or used as animal feed. ${ }^{2}$ Agricultural residues are lignocellulosic materials. ${ }^{3}$ Therefore, these wastes are used on production of industrial products such as organic acids, biofuels, protein enriched feed, aroma compounds, bioactive secondary metabolites, microbial pigments, mushroom and enzymes as substrate. ${ }^{4}$

\section{Adverse environmental effects of agricultural production}

The use of pesticides and fertilizers has been increasing, because the human population increased rapidly, generating as a result a high demand for food. The use of pesticides is 2.5 million tons, estimating this amount per year in crops. This number is worrying because it involves a large amount of waste generated significant environmental impact, public health and food quality. It is noteworthy that this overuse increases resistance to pests. It has also been estimated that $90 \%$ of pesticides are lost air during application, so it is evident the need for an efficient delivery of these pesticides. It is here where nanotechnology offers a wide range of applications in agriculture, from the delivery of agrochemicals safely, delivering nutrients for plants and electronic devices or nanosensors. ${ }^{5}$ The water that is available is threatened by situations such as climate change and pollution caused by human activities. The needs of today's society are three: food, water and energy. But water is necessary for the food industry, as a resource and as an input for energy. This reflects a paradox, and exposes the great importance of caring for water. It is said that the biological purification systems are already insufficient for the complexity of polluting chemical compounds, so that nanomaterials are a treatment option. ${ }^{6}$ Water resources and fertile land diminished by food demand currently exists. For this problem, it must increase agricultural productivity through technology. 
Through nanotechnology, it can convert or re-use pesticides and fertilizers, which are agricultural wastes that increase pollution. These wastes can increase the immunity of the plague, plus there is a risk to human health due to bioaccumulation of pesticides in food. The use of pesticides is detected even decades after use, demonstrating the significant environmental impact of this waste with marine and land species of animals. ${ }^{7}$ In agricultural production is looking for an efficient use of agricultural inputs, to avoid environmental pollution by fertilizers and pesticides. Nanoparticles have been used to produce fertilizers, pesticides and growth stimulants. Some applications of the nanoparticles, in cleaning contaminated agrochemicals soils are, fertilizers such slow release of phosphorus that is available only under specific conditions, for example, only near the root of the plant to prevent the low availability of phosphorus in plants by extreme acid and alkaline reaction. We have also found how to concentrate the ammonium nanoparticles thus recycling this chemical for use as fertilizer. Also, nutrients and controlled release of growth hormones, like explained with phosphorus is applicable. ${ }^{8}$ Nanotechnologyenabled devices can be used to monitor soil conditions and crop in real time. This implies a better use of inputs used in agriculture, water, pesticides or fertilizers, also involving a decrease in production costs. agricultural production is also increased, to monitor crop yields.?

\section{Main agricultural pollutants generated (accumulation of pesticides and fertilizers)}

Many of the activities or farming generate heavy pollution to water, either with chemicals that are used constantly in this type of work, such as pesticides and fertilizers as well as pesticides, sediment, minerals and other nutrients. They can also be found pathogens originating from faecal matter used in crops. ${ }^{9}$ In the case of pesticides, these are widely used in agriculture, for multiple applications in eliminating pests, which include: insects, mice, contaminated plants, fungi, viruses in the fields, bacteria, among others. However, in the past these were mass produced, without consideration, that many of these, especially organophosphates and organochlorines, were persistent and toxic to the environment. Which it has instead created new pests and has an adaptation of new plant diseases. And certain implications for the health of humans and animals. ${ }^{7}$ Such a case can be exposed in developed countries like the United States, which can consume up to 73 million pounds of organophosphates in the agricultural and residential sector, this as a fact of 2001. Notably obtained one of the responsible entities for environmental protection, as is the Agency for Environmental protection. It emphasizes that exposure to pesticides can occur through water, food and residential use of pesticides. These last ones are a source of fairly common and direct exposure, however, it is in the diet, where there is greater manifestation of pesticides. This can be seen in the Pesticide Data Program of the United States, in 2008. Here the existence of obvious concentrations of organophosphate malathion, which can be found in samples of frozen blueberries (28\%), strawberries sample $(25 \%)$ and celery $(19 \%){ }^{10}$

With the development of technology in the detection of organic chemicals and traces of them, even of the scale of micrograms or nanograms per liter, it has favored the detection and subsequently a possible elimination of emerging pollutants. Currently, the literature refers to the industrial area, as one that affects most to the large amount of pollutants emitted into the atmosphere, inside which include: personal care products (ibuprofen, estrioles, HHCB, triclosan, acetaminophen, DEET) and pesticides (benomyl, carbendazim, aldrin, malathion, cypermethrin, diazinon, methoxychlor, among others). These pollutants mentioned, emerge as a danger to freshwater environments and human health. ${ }^{11}$ One of the specific crops, which will be discussed in the article, is the banana and plantain, during the production of these fruits, large amounts of inorganic chemicals are applied. This, therefore for a cheap fruit, which does not have stains, so will be applied and frequent intense number of agrochemicals. There is also an abundant use of herbicides to keep an area free of vegetation, and the use of nematicides, which are used directly on the ground, surrounding trees, to prevent the roots can be damaged by nematodes. These agrochemical fungicides are added, which are used to prevent destructive fungi. Therefore, this crop and subsequent food, has a large exposure to multiple chemicals, which can not only be harmful to human health, but which generate large waste, which are accumulated in the soil, water and others. ${ }^{12}$

\section{Nanostructures and nanomaterials that eliminate the harmful components of agricultural ecosystems}

Nanotechnology to manipulate materials at the atomic and molecular level, allowing them to acquire different functions, such as to detect a contaminant in specific. Nanoparticles, can create nanosensors that are precise and sensitive to detect contaminants from water or air. In the manufacturing process, they can be used and less toxic compounds can reduce the production of harmful waste through nanotechnology. It is possible to reduce soil and water pollution by harmful chemical fertilizer product since slow release pesticides are developed through precision agriculture. Nanotechnology contributes to water treatment and allows the development of renewable energy sources..$^{13}$ A range of nanomaterials are most frequently used in agricultural applications. Include various percentages article Ruud J.B. Peters (2016), which indicates that the nanoencapsulated materials correspond to $26 \%$, and is one of the most frequently used materials as a pesticide or supplements (food ingredient). Inorganic nanomaterials have also often used in percentages of $29 \%$ metal, $26 \%$ metal oxide, $6 \%$ of carbon based materials and $6 \%$ clay. nanocomposites are then highlighted with a $7 \%$ frequency applications. Also important is the frequent use of chitosan as a biocide and as a food contact material. ${ }^{14}$ Examples of nanomaterials in remediation has been reported carbon nanotubes as a sensor for $\mathrm{H}_{2} \mathrm{~S} \mathrm{SO}_{2}$, absorption of $\mathrm{Zn}$ (II) fluoride, water dichlorobenzene, ion absorption of $\mathrm{Pb}^{2+}, \mathrm{Cu}^{2+}$ and $\mathrm{Cb}^{2+}$. Iron has been used in nitrate removal from water and arsenic removal and barium ions. Titanium dioxide is used in photovoltaic cells, eliminating benzene and toluene, and phenol photodecomposition. The silica is used as a biologically safe insecticide. ${ }^{13}$ The high price of carbon nanotubes focuses use in removing contaminants that other technologies cannot highlighting antibiotics and polar aromatics. Carbon nanotubes are studied as substitutes activated carbon as it has accessible binding sites for more molecules, especially bulky. It also serves as electron donor or acceptor substance as phenols and nitroaromatic thanks electron rich structure in $\pi$. In addition, it has been used as antimicrobial filters due to their fibrous structure, conductivity and antibacterial activity, which are more toxic when it is carbon nanotubes are metallic, dispersed and short. ${ }^{15}$ It has been found that nanosilica particles can be used for different pests, as: Sitophilus oryzae, Tribolium castaneum, Lipaphis pseudobrassicae; therefore, it is a high-performance insecticide, which causes desiccation of these organisms. It could also study nano zinc oxide as an antifungal for pathogens Aspergillus niger and Fusarium oxysporum, by the reactive oxygen species (ROS) that damage the hyphae. ${ }^{16}$ 


\section{Principle applications on the reuse of agricola wastes in nanotechnology}

Agricultural residues are parts of plant species that are not destined for consumption, which are mainly parts derived from cultivation of different species of plants (stems, leaves, shells, bark, seeds, pods, for example). The large amount of waste generated in the world are exploited in small quantities, posing a problem of environmental pollution. These residues are a source of lignocellulosic biomass, allowing greater extent exploit these agricultural wastes generating economic and environmental benefits. Waste is mainly from cereals, coffee, cocoa, tea, fruits, vegetables, cotton, among others. Potential uses of waste are as feedstock for biofuel production, production of chemicals such as butanol, acetone and ethanol, coal production, cellulose can be used to produce paper pulp. ${ }^{17}$ Industries such as packaging, automotive and construction are important in the development of natural fibers that are filled composites, generating new ecological materials. Fiber pineapple leaf is being evaluated to replace fiberglass, especially as building material. ${ }^{18}$ The waste generated from the wine industry, are an example of lignocellulosic wastes. These are generated by more than one million tons per year, in Spain. using these residues as a soil amendment, production of phenolic compounds with antioxidant activity, culture media processing to produce lactic acid and biosurfactants and inexpensive as adsorbent for heavy metals is proposed. Lignocellulosic wastes can be used for composting process other wastes, presenting some advantages, such as ease of separate compared to other raw materials collection, technology is simpler, without producing odors, low concentrations of other pollutants and they have good physical properties. ${ }^{19}$ A modification of soil with little stabilized compost can adversely affect the environment and crops, so it is important to assess compostability, which is determined during the composting process by the degree of decomposition of organic matter. The decomposition process depends on the different physicochemical properties of organic raw material used, meaning that the decomposition is a highly complex process. ${ }^{20}$

\section{Reuse of waste of banana and plantain}

Currently, there is a strong field of research in the field of green chemistry, so that the next materials and products, which are placed on the market, are biodegradable and therefore biologically based, to substitute products that Are normally obtained from the refinery or oil treatments. This is due to the attempt to take advantage of the amount of waste normally generated, which can function as biomass, to be used in obtaining a variety of products to be exploited by man. ${ }^{21}$ Banana waste generate large amounts of pseudostem, shells and other foliar residues, which are difficult to degrade and pollute the environment. ${ }^{22}$ One of the most promising compounds obtained from agricultural waste is cellulose, this is abundantly in nature and can be obtained from almost any vegetal organism. Through the vast amount of agricultural waste banana, this compound can be obtained, specifically tried a possible removal of the nanocellulose. This specifically, in the range Grand Cavendish, it has been found that in some parts of the plant such as the pseudostem is $37.85 \%$ cellulose and flower stem are to $26.86 \%$ cellulose. The importance of extracting it, lies in the possibility of replacing certain synthetic fibers that may be polluting the environment, and take advantage of large properties and characteristics at the nanoscale, offering cellulose and other components of plant origin, such as hemicellulose and lignin; for the manufacture of certain products of commercial origin. ${ }^{17}$
The nanocellulose has good features such as low density (1.6g/ $\mathrm{cm}^{3}$ ) and a reactive surface, possessing $\mathrm{OH}$ groups which facilitate attachment of certain chemicals, so they can acquire new surface properties (functionalize the surface). This modification capability enables the self-assembly facility, control of particle-particle bond, and particle-matrix. In addition, there may be transparent, has good tensile strength and a low coefficient of thermal expansion. Within the range of applications, they can be mentioned: reinforcement for polymers, biomedical, pharmaceuticals, fibers and textiles, antimicrobial films, supercapacitors, among others. ${ }^{23}$ Also, are conducting studies as mentioned, the production of bioplastics biomaterials, which are based on nanocellulose. This through biomass waste banana where it is shown that this material generated shows interesting characteristics such as: low water absorption $(0.03 \%)$, a particle size of $20 \mathrm{~nm}$, good stress $\left(120 \mathrm{MPa} / \mathrm{kg}^{*} \mathrm{~m}^{3}\right)$ among others. ${ }^{24}$

\section{Use of grape waste, pineapple, anona and other citrus}

Scientists are currently working on the concept of green nanotechnology. This integrates the principles of green chemistry and green engineering to produce eco-friendly, safe, nanoparticles that do not use toxic chemicals in their synthesis protocol. ${ }^{25}$ For this reason, producing nanoparticles of noble metals, such as gold nanoparticles (AuNP), is of great interest due to their unique characteristics. One of its applications are in semiconductors, ${ }^{26}$ spectroscopy, in biomedical applications such as drug delivery, ${ }^{27}$ tissue/tumor imaging ${ }^{28}$ and cancer therapy. ${ }^{29}$ The current method produce AuNP efficiently, however uses hazardous compounds such as hydrazine, sodium borohydride, and dimethyl formamide (DMF) as reducing agents, and may also require the use of expensive instruments..$^{30}$ In the ' Valueadding to grape waste: Green synthesis of gold nanoparticles' review they use agricultural wastes materials such as grape seed, grape skin and grape stalk to investigated the production of gold nanoparticles. Earlier studies used grape wine and grape pomace extract to reduce gold nanoparticles using $50 \mathrm{~W}$ of microwave power, ${ }^{31}$ otherwise, in that study they have isolated individual components of grape pomace like the grape seed, skin and stalk and have found that individual components have the potential to form gold nanoparticles without much agglomeration in water at room temperature, following the principles of green engineering. As well, recent studies have shown remarkable in vitro stability and affinity of gold nanoparticles synthesized from grapes towards human breast cancer cells (HBL100) biocompatibility. ${ }^{30}$ The afore mentioned paper report a simple, cost-effective procedure to produce gold nanoparticles that are stable with extended shelf life. Recent reports have shown an increased use of water as solvent in chemical reactions instead of organic solvents. ${ }^{32}$ The water dispersible nature of gold nanoparticles from grape byproducts along with its inherent health benefits can revolutionize the impact of nanotechnology on drug/nutraceutical delivery.

In tropical countries like Costa Rica, the utilization of pineapple biomass has attracted interest because of their ecological and renewable natural characteristics. At present, pineapple leaf is a waste product of pineapple cultivation. These fibers can be obtained from industries, without any additional cost input. The structure consists of vascular bundle system present in the form of bunches of fibrous cells, which are obtained after mechanical removal of all the epidermis tissues. In the other hand, the fiber is very hygroscopic, relatively inexpensive and abundant. The upper mechanical properties of PALF (pineapple leaf fiber) are because the high cellulose content, low microfrilliar angle $\left(14^{\circ}\right)$ and are found to be multicellular and lignocellulosic. ${ }^{1,5}$ The 
unique properties exhibited by pineapple leaf can be used as potential reinforcement in composite matrices and is being examined with a view to replace glass fiber in low price products, especially building materials. The method used for the separation of the nanofibers from biomass is steam explosion. Consist of high pressure steaming and rapid decompression. This process also includes saturating the dry material with steam at elevated pressure and temperature followed by sudden release of pressure, during which the flash evaporation of water exerts a thermo mechanical force causing the material to rupture. ${ }^{5}$ In this study, they achieve the extraction of pineapple a fibre for the first time applying the acid coupled steam treatment and is focus on the characterization during the steam explosion treatment (Figure 1).

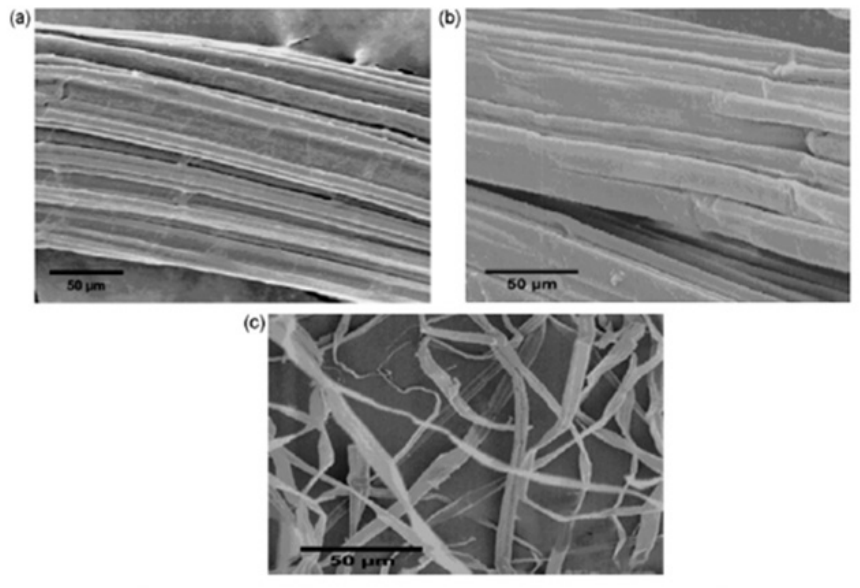

Figure I

(A) Shows the SEM of pure PALF.

(B) It is a photograph of the PALF after steam explosion treatment.

(C) SEM micrograph of the PALF after bleaching. ${ }^{23}$

\section{Identification of contaminants using nanosensors}

A nanosensor is a device with a size about 10-100 um capable of perform simple tasks in addition to detection. Is not only a nanoscale device but a device that allows the use of the properties of nanomaterials and nanoparticles to detect and measure nanoscale events.

\section{Applications in the field of agriculture}

Some of the applications uses in agriculture are: monitoring plants, detection of pests and soil monitoring. Trees, grasses, shrubs and plants generally produce many chemicals in the air to attract natural predator's insects that attack, for example, or to regulate flowering between different plantations. Chemicals nanosensors can be used to detect these chemicals and thus monitor the growth processes plants. A nanosensor in combination with nano-actuators can be used to stimulate, increase or abort some natural processes plantations, too. For example, instead of using synthetic chemicals products to control insect pests, we could apply a nano-acting network to generate the same volatile natural that attract larvae predators. Although, using wireless networks of nanosensors is possible to monitor in real time the soil conditions to determine which procedures are needed to prepare it. In that sense, there is an important interest of the US
Department of Agriculture (USDA) as priority research area. They have called "Smart fields" (smart fields). The ideal of an intelligent system of this type is to detect, locate, report and apply water, fertilizers or pesticides, so automatically. ${ }^{33}$

\section{Types of nanosensors}

i. Physical: Its operating principle is based on the fact that working principle is based on the fact that electronic properties of nanotubes or nanoribbons1 changed when they deform. Thus, for example a local deformation of a pipe creates a change in the voltage.

ii. Chemicals: Its operating principle is based on the fact that electronic properties of nanotubes or nanoribbons change when absorbed different types of molecules, which increases or decreases the number of electrons able to move in the system. Therefore, the presence of a specific type of molecule, changes the threshold of voltage.

iii. Mechanical: Measured types of mechanical parameters such as distances, positions, levels and movements. In some classifications, these sensors can be part of physicists.

iv. Biological: Usually, is composed of a biological recognition system (bioreceptor). This system can be an antibody, an enzyme, a protein or a strain of DNA, and a transducer mechanism such as an electrochemical detector, an optical transducer or a magnetic detector ${ }^{33}$ (Figure 2).

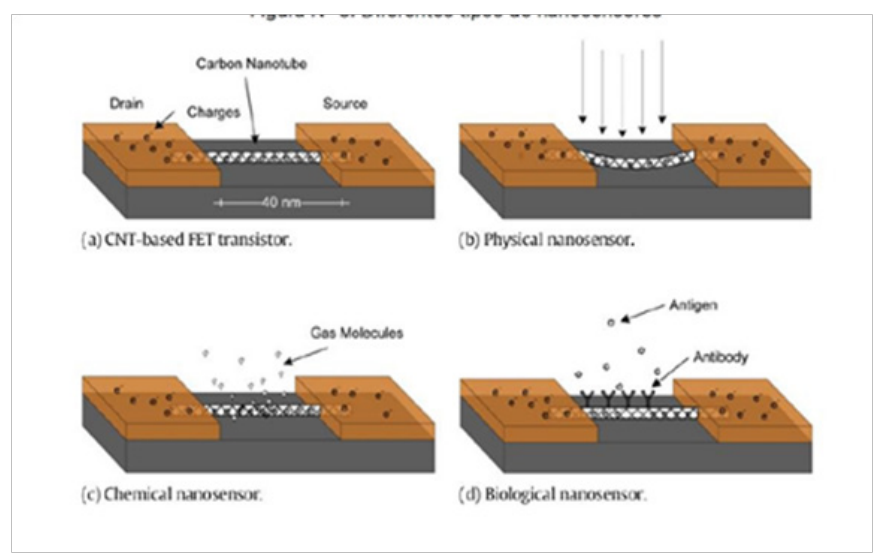

Figure 2 Types of nanosensors. ${ }^{36}$

\section{Nanosensors in agriculture}

In 2004, the first biosensor to measure the activity of soil microorganisms was build. This biosensor can record if there is any possible of soil diseases. This device estimate the relative of activity of favorable and unfavorable microbes in the soil determined based on differential oxygen consumption in their respiration. Therefore, it is achievable to predict beforehand if there is or not a soil disease in the test. ${ }^{34}$ Also, there are toxic metabolites produced by several fungi in foods and feeds known as mycotoxin. Mycotoxins produce adverse health effects, some of them are carcinogenic, vasoactive or cause damage to the central nerve system. Experiments with environmental biosensors are focused on molecular affinity reactions such as antibody-antigen interactions. This interaction is achieved in low concentrations. For this, there are immunochemical biosensors applied for mycotoxin assays. And Gaag at al. developed a method based on surface plasmon resonance for measuring of four different 
mycotoxins - aflatoxin B1, zearalenone, ochratoxin A and fumarotoxin $\mathrm{B} 1 .{ }^{35}$

\section{Elimination of agrochemicals}

Today, thanks to nanotechnology, can perform multiple detections of chemicals and other compounds that may be toxic to people. Applications such as the use of nanoparticles coupled to antibodies, can generate light to detect certain substances, it can be used to enter, as being made in the identification and quantification of agrochemicals, such as pesticides. Also, nanotechnology has allowed inroads into applications photocatalysis, in which by the reaction of light with certain materials, such as pesticide residues, coupled to a nanomaterial, can eliminate them and therefore decontaminate water. ${ }^{36}$ Photocatalysis applications have been studying coupled to nanotechnology, which offers better results and the possibility of eliminating certain toxic compounds. In one of the investigations, it presents a way to remove compounds such as analgesics (acetaminophen and antipyrine), testosterone, bisphenol, caffeine, o-phenylphenol (fungicide and bactericide) and herbicides (terbuthylazine, diuron, MCPA); the latter being mentioned compounds of interest for this section to be analyzed. The mentioned compounds can be eliminated by means of oxidation processes based on solar radiation, including photo-Fenton oxidation treatments led catalytically with iron or ozonation and $\mathrm{TiO}_{2}$; and combinations of these techniques. ${ }^{37}$ Photocatalysis, can be carried out either with metal nanoparticles or metal oxides (semiconductor), including may be mentioned: $\mathrm{TiO}_{2}$ (widely used), $\mathrm{ZnO}, \mathrm{Fe}_{2} \mathrm{O}_{3}, \mathrm{Au}$, among others. These provide physicochemical and optoelectronic, important for use as photocatalysts characteristics. ${ }^{38}$ From the beginning, in the technique of photocatalysis, $\mathrm{TiO}_{2}$ has been used as an optimum material for these processes. This is due to the high capacity in its electronic properties, structure and morphology, which make a compound of $\mathrm{TiO}_{2}$ with good photocatalytic performance. In recent years, it has been working with these structures but as nanowires and nanotubes, which could be obtained by highly aligned growth from Titanium as substrate..$^{39}$

To understand photocatalysis and how it can intervene in the process of degradation of pollutants, it is necessary to understand the main reaction steps or stages thereof. This process begins when light of higher energy than the band gap, impacts a semiconductor such as $\mathrm{TiO}_{2}$, then the promotion of an electron is generated from the valence band to the conduction band, which creates a hole in the valence band (this as $\mathrm{H}+$ ). The $\mathrm{H}+$, together with the electron diffuse into the respective band of the semiconductor and then proceed to react with a redox species in the environment. When in water, the energy generated, not only allows the dissociation of the same into oxygen and hydrogen, but also favors the formation of radicals $(\mathrm{OH}$ -) (Figure 3). The latter are what make possible the oxidation of a large amount of inorganic and organic compounds. ${ }^{39}$ As the above mechanism, one of the main uses of photocatalysts is generate ROS known, also named as highly reactive oxygen species, which already mentioned that generally present as hydroxyl radicals explained (can perform degradation of organic pollutants). Photocatalysts can provide an efficient, cost effective and promising technology not only for the degradation of organic compounds, but for possible biological disinfection, including applications in the wastewater treatment. ${ }^{40}$

Among the photocatalysts can be found in recent studies, the facts shown graphene. Among them, a widely used are the $\mathrm{CdS} /$ graphene nanocomposites, which may have applications as artificial photosynthetic systems, organic photosynthesis and environmental remediation. This last application is very useful for the photodegradation of contaminants found on the surface of these photocatalysts. ${ }^{41}$ Another way is the synthesis of compounds as graphite oxide $/ \mathrm{TiO}_{2}$, efficient photocatalyst, which can be subjected then to calcination at $200^{\circ} \mathrm{C}$. This post-calcination temperature improves the effectiveness of the photocatalyst and the $\mathrm{pH}$ of the solution and graphene oxide content. The efficiency of the compound is due to the fine dimensional layer, a large surface area and good absorption capacity, apart from a suitable electronic transfer, by reducing the graphene oxide. ${ }^{42}$

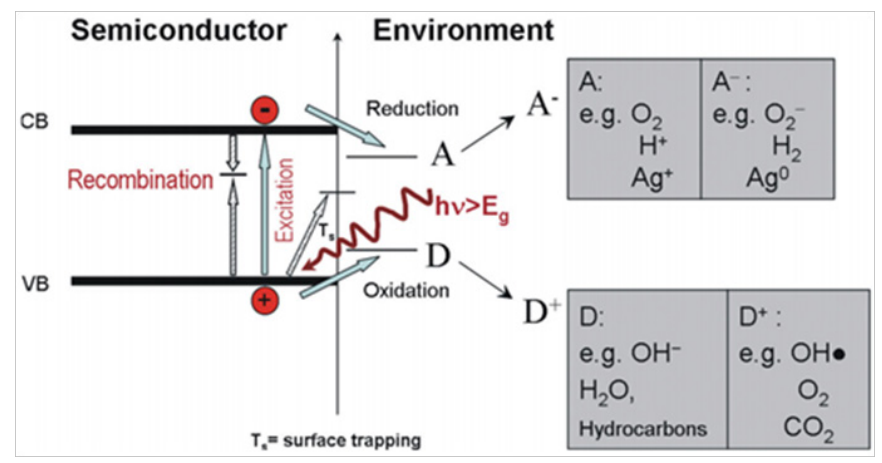

Figure 3 Scheme of photo-induced processes at a $\mathrm{TiO}_{2}$ a semiconductor/ electrolyte interface. Light (hv) excites valence band electron to conduction band. Electron and hole react with environment acceptor (A) and/or donor (D). Acceptor and donor species are reduced and oxidized (=photocatalytic efficiency). Greys boxes give typical reactants and reaction products in photocatalytic reactions on $\mathrm{TiO}_{2}$.

\section{Disadvantages and risks of nanotechnology applied in agriculture}

Agricultural nanotechnology is a tool that can provide greater dividends for poor nations because it is powerful in ameliorating problems related to poor input use efficiency, water scarcity, poor sanitary conditions, and other similar problems experienced by nations with poor resources. However, these nations can harvest the fruits of nanotechnology if it is realized that future cost of importing farm-technology could be higher than that of developing it indigenously in a sustained manner. ${ }^{43}$ Besides of the benefits in the emerging nations, nanotechnology will bring significant benefits to the agri-food industry and consumers including more efficient food production methods, the development of functional foods which offer health claims, increased shelf life of food products, more hygienic food processing, and improved traceability and safety of products. ${ }^{44,45}$ However, despite these actions, it is difficult to know how widespread the application of nanotechnology is in the agri-food sector because there is limited research on the industry's actual awareness of nanotechnology or how it is being applied. So, that, several uncertain factors relating to health and safety, indicates that the incorporation of nanomaterials into food products and packagings may present an entire new array of risks for consumers. ${ }^{46}$ In the present, there is little regulation regarding nanotechnologies or nanoproducts. ${ }^{47}$ There are a few government agencies from different countries have established regulatory frameworks for the use of nanotechnology; these are extensive enough to cover agri-food applications. ${ }^{48}$ Further, consumers are found to be more accepting of packaging (Nanooutside) than products that incorporate nanomaterials within the food (Nano-inside) which they consider to be riskier. 
About the legislation on the use of nanotechnology, now there are regulation and oversight of environmental, health and safety (EHS) risks associated with nanotechnology markets have been undergoing significant developments in the EU; many were intertwined with adaptations or recast of existing regulatory frameworks. Amendments have been done of the chemicals policy ${ }^{49}$ followed by adaptations of the food policy. ${ }^{50}$ The European Commission (EC) also established two horizontal nano-specific measures, the code of conduct for responsible nanosciences and nanotechnologies $(\mathrm{N} \& \mathrm{~N})$ research $^{49}$ and a recommended 'nanomaterials' definition for regulatory purposes. ${ }^{51}$ Finally, we must also considerate serious organizational issues in the adoption of nanotechnologies; for small and medium enterprises (SMEs), innovation may be constrained by limited resources and difficulties to access research and know how to implement such technologies. ${ }^{46}$

\section{Obstacles to the adoption of nanotechnology}

A larger scale material has different physical, chemical, biological and toxicological properties, compared to the same material in atomic and molecular scale. Due to its large contact area, nanomaterials can have toxic effects, because they are biologically more active than the bulk material. However, although they are new materials at the nanoscale, no studies on its potential toxicity to living things are made. ${ }^{52,53}$ The benefits of nanotechnology in agriculture are evident, however, market interests take precedence, with the health of production workers nanoparticles. It may be linked ignorance of this new technology, with the fact that there are no regulations governing the production of nanoparticles. Depending on the route of entry of these nanoparticles to an organism (inhalation, ingestion and penetration through the skin), a risk scale is associated. There is increased risk of nanoparticles in solid form, of second risk are those that are suspended in liquids, third risk which are fixed in matrices and finally incorporated nanostructures are, those with lower risk. ${ }^{52,53}$ Strategic Studies of the Organization for Economic Cooperation and Development (OECD) are based on the intrinsic properties of each material, in this case of engineered nanoparticles, along with animal and environmental toxicity, environmental degradation and accumulation. Importantly, few studies emphasized terrestrial plants, plus many results of the negative effects of the plant-nanoparticle interactions are performed in high doses and short exposure, which moves away from the real potential risk of nanoparticles. a change in the experimental design, making realistic scenarios studies and long term, to have a more precise idea about the phytotoxicity of engineered nanoparticles is necessary. ${ }^{54}$

In many countries, the incineration of municipal solid waste is performed, as one of the tasks of daily cleaning, reaching incineration quantities of over 100 million tons, however, despite the high temperatures, if present nanomaterials, the existence of these in waste remains constant. This demonstrated by a study in which nanoparticles of cerium oxide was used, introduced the same either before the incineration process as well as the output current of the incinerator furnace gas. These binds weakly to solid waste during the combustion process, although are achieved filtered through current technology, nanoparticles end attached to solid waste entering either landfilled or leaving raw materials, which they have been recovered. ${ }^{55}$ The opinion, perception and public acceptance are crucial factors in advancing nanotechnology, so that the development of this technology is parallel to the economic and social impacts. Based on surveys, society does not know much about nanotechnology. The perceived risk is an important factor, and can reduce concern about this technology if there is greater confidence in the government agencies charged with regulating nanotechnology. The surveys also showed that people have low preference to buy nanotech food, however the nanotechnological packaging have better acceptance, so that within the nanotechnological context, the containers are perceived more beneficial than food. ${ }^{56}$

\section{Legislation and importance of nanotechnology in agriculture}

Currently, the legislation related to specific applications of nanotechnology in any field is poor. The relevant European regulations that are important extends from Reach (the EC Regulation No. 1907/2006 on Chemicals, aimed at preventing harm to humans or the environment), through the Waste Framework Directive 2008/98/EC to the Novel Foods Regulation (EC) No. 258/97). ${ }^{47}$ Also, nanotechnology is used in a variety of food applications but there is not a printed list of food products that involve nanotechnology for that reason it is difficult to estimate the impact of nanotechnology in food and agriculture. ${ }^{57}$ This is not the case in industries, who had been forced to enforce very specific information on nanomaterials in their products. An example of this, it is Article 16 of European Cosmetics Regulation (Regulation (EC) 1223/2009) that outlines specific requirements related to nanomaterials in cosmetics. ${ }^{57}$

\section{Acknowledgements}

None.

\section{Conflict of Interest}

The author declares no conflict of interest.

\section{References}

1. Food wastage Footprint-Impacts on natural resources: summary report. Food and Agriculture Organization of the United Nations, Europe: Springer; 2003

2. Tepe O, Dursun AY. Exo-pectinase production by Bacillus pumilus using different agricultural wastes and optimizing of medium components using response surface methodology. Environ Sci Pollut Res In. 2014;21(16):9911-9920.

3. Chandra R, Takeuchi H, Hasegawa T. Methane production from lignocellulosic agricultural crop wastes: a review in context to second generation of biofuel production. Renew and Sustain Energy Rev. 2012;16(3):1462-1476

4. Singh Nee Nigam P, Pandey A. Biotechnology for agro-industrial residues Utilisation. In: Poonam Singh Nigam et al. editors. Netherlands: Springer; 2009. $466 \mathrm{p}$.

5. De Oliveira JL, Campos EV, Bakshi M, et al. Application of nanotechnology for the encapsulation of botanical insecticides for sustainable agriculture: prospects and promises. Biotechnology Advances. 2014;32(8):1550-1561.

6. Gelover Santiago SL. Nanotecnología, una alternativa para mejorar la calidad del agua, mundo nano. Revista Interdisciplinaria en Nanociencia y Nanotecnología. 2015;8(14):40-52.

7. Baruah S, Dutta J. Nanotechnology applications in pollution sensing and degradation in agriculture: a review. Environ Chem Lett. 2009;7(3):191204. 
8. Carrillo González R, González Chávez MDCA. La nanotecnología en la agricultura y rehabilitación de suelos contaminados. Revista Interdisciplinaria en Nanociencia y Nanotecnología. 2009;2(2).

9. Aguilar A, Pérez Espejo, Anne M, et al. Agricultura y contaminación del agua. (Primera Edición), México: Universidad Nacional Autónoma de México; 2012

10. Bouchard MF, Bellinger DC, Wright RO, et al. Attention-deficit/ hyperactivity disorder and urinary metabolites of organophosphate pesticides. Pediatrics. 2010;125(6):1270-1277.

11. Murray KE, Thomas SM, Bodour AA. Prioritizing research for trace pollutants and emerging contaminants in the freshwater environment Environmental Pollution. 2010;158(12):3462-3471.

12. Rossi D. Los Agroquímicos usados en Las Plantaciones Bananeras y sus Efectos en el Agua, la Gente, y el Ambiente en la Comunidad de Changuinola, Panamá. Bocas del Toro, USA: Lehigh University; 2013.

13. Das S, Sen B, Debnath N. Recent trends in nanomaterials applications in environmental monitoring and remediation. Environ Sci Pollut Res Int 2015;22(23):18333-18344.

14. Peters RJ, Bouwmeester H, Gottardo S, et al. Nanomaterials for products and application in agriculture, feed and food. Trends in Food Science \& Technology. 2016;54:155-164.

15. Qu X, Brame J, Li Q, et al. Nanotechnology for a safe and sustainable water supply: enabling integrated water treatment and reuse. Accounts of chemical research. 2012;46(3):834-843.

16. Qu X, Brame J, Li Q, et al. Nanotechnology for a safe and sustainable water supply: enabling integrated water treatment and reuse. Accounts of chemical research. 2012;46(3):834-843.

17. Carchi D. Aprovechamiento de los Residuos Agrícolas provenientes del cultivo de Banano para obtener Nanocelulosa. Ecuador; Universidad de Cuenca; 2014.

18. Cherian BM, Leão AL, De Souza SF, et al. Isolation of nanocellulose from pineapple leaf fibres by steam explosion. Carbohydrate Polymers. 2010;81(3):720-725.

19. Paradelo R, Moldes AB, Barral MT. Evolution of organic matter during the mesophilic composting of lignocellulosic winery wastes. $J$ Environ Manage. 2013;116:18-26.

20. Mondini C, Sánchez-Monedero MA, Sinicco T, et al. Evaluation of extracted organic carbon and microbial biomass as stability parameters in ligno-cellulosic waste composts. J Environ Qual. 2006;35(6):23132320 .

21. Abdul $\mathrm{KH}$, Bhat $\mathrm{AH}$, Ireana A. Green composites from sustainable cellulose nanofibrils: A review. Carbohydrate Polymers. 2012;87(2):963979.

22. Mazzeo M, León L, Mejía L, et al. Aprovechamiento industrial de residuos de cosecha y poscosecha del plátano en el departamento de caldas. Revista Educación en Ingeniería. 2010;9:128-139.

23. Moon R, Martini A, Nairn J, et al. Cellulose nanomaterials review: structure, properties and nanocomposites. Chem Soc Rev. 2011;40(7):3941-3994.

24. Sharif Hossain AB, Ibrahim NA, Al Eissa MS. Nano-cellulose derived bioplastic biomaterial data for vehicle bio-bumper from banana peel waste biomass. Data Brief. 2016;8:286-294.

25. Castro L, Blazquez M, Munoz J, et al. Biosynthesis of gold nanowires using sugar beet pulp. Process Biochem. 2011;46(5):1076-1082.

26. Schmid KF. Green nanotechnology: it's easier than you think (Report). USA: Project on emerging nanotechnologies; 2007. p. 1-36.
27. Mahal A, Khullar P, Kumar H, et al. Green chemistry of zein protein toward the synthesis of bioconjugated nanoparticles: understanding unfolding, fusogenic behavior, and hemolysis. ACS Sustainable Chem Eng. 2013;1(6):627-639.

28. Jain PK, Lee KS, El-Sayed IH, et al. Calculated absorption and scattering properties of gold nanoparticles of different size, shape, and composition: applications in biological imaging and biomedicine. J Phys Chem B. 2006;110(14):7238-7248.

29. Peng G, Tisch U, Adams O, et al. Diagnosing lung cancer in exhaled breath using gold nanoparticles. Nat Nanotechnol. 2009;4(10):669-673.

30. Krishnaswamy K, Vali H, Orsat V. Value-adding to grape waste: Green synthesis of gold nanoparticles. Journal of Food Engineering. $2014 ; 142: 210-220$

31. Baruwati B, Varma RS. High value products from waste: grape pomace extract-a three-in-one package for the synthesis of metal nanoparticles. ChemSusChem. 2009;2(11):1041-1044.

32. Li CJ, Chen L. Organic chemistry in water. Chem Soc Rev. 2006;35(1):6882.

33. Estudios de Consultoría en el Sector Nanotecnológico. El Futuro De Las Nanociencias Y Las Nanotecnologías En Argentina Estudio De Prospectiva Y Vigilancia Tecnológica. España; 2013. p. 1-240.

34. Baruah S, Dutta J. Nanotechnology applications in pollution sensing and degradation in agriculture: a review. Environmental Chemistry Letters. 2009;7(3):191-204.

35. Yotova L, Yaneva S, Marinkova D. Biomimetic nanosensors for determination of toxic compounds in food and agricultural products. Journal of Chemical Technology and Metallurgy. 2003;48(3):215-227.

36. Molins R. Oportunidades y amenazas de la nanotecnología para la salud, los alimentos, la agricultura y el ambiente. Perspectivas. 2008;4:38-52.

37. Hernán D. Eliminación de contaminantes emergentes del agua mediante ozonación solar fotocatalítica (Tesis Doctoral). Universidad de Extremadura, Spain: Springer; 2015.

38. Zeng Z, Liu S, Cai J, et al. Immobilized $\mathrm{TiO}_{2}$ Photocatalytic in cellulose matrix for degradation of phenol under UV light irradiation weak. J Phys Chem C. 2010;114:7806-7811.

39. Paramasivam I, Jha $\mathrm{H}$, Liu N, et al. A review of photocatalysis using selforganized $\mathrm{TiO}_{2}$ nanotubes and other ordered oxide nanostructures. Small. 2012;8(20):3073-103.

40. Hoang S, Gao P. Nanowire Array structures for photocatalytic energy conversion and utilization: a review of design concepts, assembly and integration, enabling and function. Adv Energy Mater.2016;6(23):1-29.

41. Li Q, Li X, Wageh S, et al. CdS/Graphene Nanocomposite photocatalysts. 2015;5(14).

42. Jiang $\mathrm{G}$, Lin $\mathrm{Z}$, Chen $\mathrm{C}$, et al. $\mathrm{TiO}_{2}$ nanoparticles on graphene oxide nanosheets assembled with high photocatalytic activity for removal of pollutants. CARBON. 2011;49(8):2693-2701.

43. Mukhopadhyay SS. Nanotechnology in agriculture: prospects and constraints. Nanotechnol Sci Appl. 2014;7:63-71.

44. Chaudhry Q, Scotter M, Blackburn J, et al. Applications and implications of nanotechnologies for the food sector. Food Addit Contam Part A Chem Anal Control Expo Risk Assess. 2008;25(3):241-258.

45. Ranjan S, Dasgupta N, Chakraborty AR, et al. Nanoscience and nanotechnologies in food industries: opportunities and research trends. Journal of Nanoparticle Research. 2014;16:2464-2487.

46. Handford CE, Dean M, Spence M, et al. Awareness and attitudes towards the emerging use of nanotechnology in the agri-food sector. Food Control. 2015;57:24-34. 
47. Coles D, Frewer LJ. Nanotechnology applied to European food production - A review of ethical and regulatory issues. Trends in Food Science and Technology. 2013;34(1):32-43.

48. Mantovani E, Porcari A, Morrison MD, et al. Developments in nanotechnologies regulation and standards 2011-Report of the observatory nano. UK: Institute of Nanotechnology; 2011. p. 1-21.

49. Regulation (EC) no 1907/2006 of the European parliament and of the council on the registration, evaluation, authorization and restriction of chemicals (REACH) as regards annexes IV and V. Off J Eur Union L. 2006;906:268.

50. Regulation (EC) no 1333/2008 of the European parliament and of the council of 16 December 2008 on food additives. Off J Eur Union L. 2008;345:16.

51. Commission recommendation of 18 October 2011 on the definition of nanomaterials (EC). Off J Eur Union L. 2011;275:38.

52. Foladori G. Trabajadores y nanotecnología. Observatorio del desarrollo: Investigación, reflexión y análisis. 2012;1(3).
53. Sozer N, Kokini J. Nanotechnology and its applications in the food sector. Trends in biotechnology. 2009;27(2):82-89.

54. Servin AD, White JC. Nanotechnology in agriculture: Next steps for understanding engineered nanoparticle exposure and risk. NanoImpact. 2016;1:9-12.

55. Walser T, Limbach LK, Brogioli R, et al. Persistence of engineered nanoparticles in a municipal solids-waste incineration plant. Nature Nanotechnology. 2012;7:520-524.

56. Scholz RW, Siegrist M. Low risks, high public concern? The cases of persistent organic pollutants (POPs), heavy metals, and nanotech particles. Human and Ecological Risk Assessment. 2010;16(1):185-198.

57. Jones R. Nanotechnologies and food, house of lords, science and technology committee, $1^{\text {st }}$ Report of Session 2009-10, Vol I. Report, London, UK: Springer; 2009. p. 1-112.

58. Khot LR, Sankaran S, Maja JM, et al. Applications of nanomaterials in agricultural production and crop protection: a review. Crop protection. 2012;35:64-70. 